\title{
Proposed Public Charge Rule Would Significantly Reduce Legal Admissions and Adjustment to Lawful Permanent Resident Status of Working Class Persons
}

\author{
Donald Kerwin, Robert Warren, and Mike Nicholson
}

\section{Introduction}

On October 10, 2018, the US Department of Homeland Security (DHS) issued its long-anticipated proposed rule on inadmissibility on public charge grounds. ${ }^{1}$ The rule seeks to "better ensure" that applicants for admission to the United States as immigrants (permanent residents) and nonimmigrants (temporary residents), ${ }^{2}$ as well as applicants for adjustment to lawful permanent resident (LPR) status within the United States, will be "self-sufficient" and "not depend on public resources to meet their needs, but rather rely on their own capabilities and the resources of their family, sponsor, and private organizations." ${ }^{3}$ Under the proposed rule, US Citizenship and Immigration Services (USCIS) officers would consider receipt of cash benefits and, in a break from the past, non-cash medical, housing, and food benefits in making public charge determinations. The proposed DHS rule details the factors - positive and negative - to be weighed in these decisions.

Many commentators have sharply criticized the proposed rule, arguing that it would:

- Deny admission and adjustment to large numbers of low-income persons who contribute substantially to the US economy, have US citizen and LPR family members, and present a very low risk of becoming financially dependent on the government.

- Create a disincentive to the use of public benefits to meet the essential food, housing, and medical needs of US citizen, LPR, and other family members of persons who are directly affected by the rule.

- Impede the legal immigration and integration of low-income, working-class immigrants and their families to the detriment of US communities and society.

The authors share these concerns, but the study focuses more narrowly on the potential effect of the proposed rule on two populations, undocumented immigrants and nonimmigrants that would otherwise be eligible for LPR status based on a legally qualifying relationship to a US citizen or LPR living in their household. The Center for Migration Studies (CMS) report analyzes how these populations in 2016 would have fared under the proposed rule.

1 Inadmissibility on Public Charge Grounds, 83 Fed. Reg. 51114 (proposed October 10, 2018) (to be codified at 8 CFR Parts 103, 212, 213, 214, 245 and 248) [hereinafter “DHS Proposed Public Charge Rule"].

2 Nonimmigrants are noncitizens admitted for a temporary period and a particular purpose, such as foreign students or temporary workers.

3 DHS Proposed Public Charge Rule § III A. 
After placing the rule in historic context, the paper profiles these two populations and examines the characteristics that would mitigate in favor of and against their inadmissibility. The study offers a snapshot of these two groups based on estimates derived from the 2016 American Community Survey (ACS). It concludes that:

- 2.25 million undocumented persons and 212,000 nonimmigrants would be directly affected by the proposed rule because they live with a US citizen or LPR family member who can petition for them.

- These two groups live in households with an additional 5.32 million and 456,000 persons respectively, who would be indirectly impacted by the rule.

- CMS's estimates exclude several populations - such as the millions residing abroad who are waiting for a visa to become current (available) - that would be subject to the rule. Thus, the study substantially understates the number of persons who would be directly and indirectly affected by the rule.

- A large percentage of the 2.25 million undocumented persons examined would be found inadmissible under the rule, although this population overwhelmingly consists of workingclass persons.

- As a result, the proposed rule should be viewed as a significant barrier to legal immigration and the integration of low-income immigrants and their US families.

- Far lower rates of nonimmigrants - who earn more than the undocumented and have higher levels of education - would be found inadmissible under the rule.

- The numbers and percentages of persons who would be found inadmissible under the rule cannot be predicted with precision due primarily to the discretion afforded USCIS officials in making inadmissibility determinations.

\section{Historical Background and Proposed DHS Rule}

For nearly 140 years, noncitizens have been found inadmissible or deportable if deemed to be, or deemed likely to become, a public charge. The Immigration Act of 1882 provided for the exclusion of "any convict, lunatic, idiot, or any person unable to take care of himself or herself without becoming a public charge." 4 The Immigration Act of 1891 excluded "paupers or persons likely to become a public charge" and required the return of "any alien" who became a public charge within one year "from causes existing prior" to their arrival. ${ }^{5}$

Under current law, any noncitizen "who, in the opinion of the consular officer at the time of application for a visa, or in the opinion of the Attorney General [now USCIS] at the time of application for admission or adjustment of status, is likely at any time to become a public charge" is inadmissible, ${ }^{6}$ and any noncitizen who "within five years after the date of entry; has become

4 Immigration Act of 1882, 22 Stat 214 (August 3, 1882). http://library.uwb.edu/Static/USimmigration/22\%20 stat\%20214.pdf.

5 Immigration Act of 1891, 26Stat. 1084, §§1,11 (March3,1891). http://library.uwb.edu/Static/USimmigration/26\%20 stat\%201084.pdf.

6 Immigration and Nationality Act (INA) § 212(a)(4)(A). 
a public charge from causes not affirmatively shown to have arisen since entry" is deportable. ${ }^{7}$ However, deportation is very rare under this provision (INS 1999; Singer and Harrington 2018).

The Immigration and Nationality Act (INA) minimally requires USCIS officials and US Department of State (DOS) consular officers to take into account the intending immigrant's age; health; family status; assets, resources, and financial status; and education and skills. ${ }^{8}$

The Illegal Immigration Reform and Immigrant Responsibility Act of 1996 (IIRIRA) ${ }^{9}$ introduced new sponsorship rules that require US citizens and LPRs to file an affidavit of support (AOS) that commits them to "maintain" the intending immigrant at an annual income of at least 125 percent of the federal poverty guidelines (FPG), until he or she either naturalizes or works 40 "qualifying quarters." ${ }^{10}$ During this period, any federal, state or local government can seek reimbursement from the sponsor (typically the petitioner) for the cost of any "means-tested public benefit" used by the intending immigrant. ${ }^{11}$ If the sponsor cannot meet the income requirements, the INA allows for co-sponsors and the use of "significant assets" to make up the difference in income. ${ }^{12}$

The term "likely to become a public charge" has never been defined by statute, leaving it to the courts and implementing agencies to clarify its meaning. To that end, in May 1999, the Immigration and Naturalization Service (INS) issued a proposed rule and field guidance that provided that the public charge grounds applied to noncitizens who had "become (for deportation purposes) or who [are] likely to become (for admission/adjustment purposes) 'primarily dependent on the government for subsistence, as demonstrated by either (i) the receipt of public cash assistance for income maintenance or (ii) institutionalization for long-term care at government expense'" (INS 1999).

Under the INS's totality of the circumstances framework, INS/USCIS officers could consider the use of public benefits for "cash assistance for income maintenance and institutionalization," including Supplemental Security Income (SSI), Temporary Assistance for Needy Families (TANF) cash assistance, state and local cash assistance ("General Assistance" programs), and programs like Medicaid that support long-term institutionalized care. The INS guidance did not provide for the consideration of non-cash benefits in this determination.

Over the last 20 years, DOS's public charge definition rested heavily on the sufficiency of the AOS (Wheeler 2018). In early 2018, however, without notice and comment, DOS updated its Foreign Affairs Manual (FAM) to make a sufficient AOS just one "positive factor" in a totality of the circumstances framework that considers the intending immigrant's age; health; family status; assets, resources, financial status; education; and skills. ${ }^{13}$ Moreover, the FAM diverges from the former INS guidelines in allowing consideration of receipt of any past or current public assistance, including non-cash benefits, by a visa applicant or a family member living in the same household. ${ }^{14}$

7 INA § 237(a)(5).

8 INA § 212(a)(4)(B)(i).

9 Pub. L. No. 104-208, 110 Stat. 3009 (1996).

10 INA $\S 213 \mathrm{~A}(\mathrm{a})(1)$ and (2). A qualifying quarter is a three-month period in which the immigrant earns enough to receive credit toward Social Security retirement benefits.

11 INA § $213 A(\mathrm{a})(1)(\mathrm{B})$.

12 INA § 213A(f)(6)(A)(ii).

139 FAM 302.8-2(B).

149 FAM 302.8-2(B)(2)(f)(1)(b)(i); Singer and Harrington $(2018,8)$. 
In publishing its proposed rule, DHS formally withdrew the INS guidance. The DHS rule still applies to noncitizens who seek an immigrant or nonimmigrant visa, adjustment of status, or an extension of their stay in the United States or a change of nonimmigrant status. It does not apply to DOS consular officers. However, DHS anticipates that DOS will revisit its guidelines in order to avoid issuing visas to persons who would be deemed inadmissible under the rule.

The DHS proposed rule affirms the totality of the circumstances framework and the prospective character of public charge determinations. It allows consideration of "all the factors bearing on" the intending immigrant's ability or potential ability to be self-sufficient. ${ }^{15}$ It would not require "primary dependence" on public benefits for a finding of inadmissibilty, but would count "receipt of financial support from the general public through government funding." ${ }^{16}$ In addition, it would take into account cash benefits and non-cash medical, housing, and food benefits. ${ }^{17}$ Of the non-cash benefits, it would consider nonemergency Medicaid, Premium and Cost Sharing Subsidies for Medicare Part D, the Supplemental Nutrition Assistance Program (SNAP) (formerly "food stamps"), long-term institutionalization at the government's expense, Section 8 Housing Assistance and Project-Based Rental Assistance, and Subsidized Public Housing.

The proposed rule details the factors - positive and negative - to be considered in a public charge decision. They include age, health, family status, assets, resources, financial status, education, skills, and the AOS's sufficiency. ${ }^{18}$ The following factors weigh heavily in favor of inadmissibility on public charge grounds:

- Lack of employability, as demonstrated by current unemployment, poor employment history, or [few] reasonable prospects for future employment.

- Current receipt of one or more public benefit, as defined by the rule.

- Receipt of one or more public benefit within 36 months prior to filing an application for a visa or admission.

- Lack of private health insurance or the financial resources to pay for a diagnosed medical condition "that is likely to require extensive medical treatment or institutionalization" and that will interfere with the intending immigrant's ability to provide for herself, attend school, or work.

- A previous finding of inadmissibility on public charge grounds.

- A combination of assets and resources that fall below 125 percent of the FPG, as required by the AOS. ${ }^{19}$

15 DHS Proposed Public Charge Rule § III A.

16 ld., $\S \vee \mathrm{B} 1$.

17 To be covered within this definition, public benefits that can be monetized must exceed 15 percent of the FPG for a household of one for 12 consecutive months. Benefits that cannot be monetized must be received for more than 12 months in total within a 36-month period. For a combination of monetized benefits (equal to less than 15 percent of the FPGs) and non-monetized benefits, the latter must be received for at least nine months in total in a 36-month period.

18 The affidavit of support is filed by the petitioners/sponsors of intending immigrants in the overwhelming majority of family-based immigration cases, as well as in select employment-based cases.

19 DHS Proposed Public Charge Rule § V L 1. 
Other factors - like income at or above 250 percent of the FPG, and significant assets and resources - weigh heavily against a negative public charge finding. ${ }^{20}$ Lack of negative factors also mitigate against a finding of inadmissibility.

\section{Impact of Proposed Rule}

CMS has derived its estimates from 2016 ACS data (one-year estimates). ${ }^{21}$ As a result, the study offers estimates of two populations directly affected by the rule at a fixed time: undocumented immigrants and nonimmigrants who are potentially eligible for LPR status based on a legally qualifying family relationship to a US citizen or LPR living in their US household. Some of these intending immigrants will be able to adjust to LPR status in the United States and others will need to leave the country for consular processing when their visa becomes current. Both groups are included in CMS's study. However, the study does not include persons living abroad who are waiting for an immigrant visa to become current.

CMS's analysis suggests that a large number and share of working class immigrants would be denied admission and prevented from adjusting to LPR status under the proposed rule. As such, the rule might best be seen as part of a broader strategy to reduce legal migration to the United States and to impede access to citizenship (Kerwin, Alulema, and Nicholson 2018, 6).

For a half-century, "the general rule in determining public charge has been that intending immigrants who are able-bodied and employable will not be found to be inadmissible under this ground" (Wheeler 2011). Although not well-reported, the percentage and overall number of immigrant and nonimmigrant visa applications refused on public charge grounds have been relatively low (Singer and Harrington 2018, 11). The proposed rule would be a dramatic departure from the status quo. Some of the factors that favor a finding of inadmissibility under the rule like low income and low levels of education - do not typically lead to high levels of government dependency, as evidenced by the overwhelming majority of US undocumented residents who work at high rates and contribute significantly to the US economy (Warren and Kerwin 2017, 3-4).

CMS estimates that 2.25 million undocumented persons and 212,000 nonimmigrants enjoy a qualifying family relationship to a US citizen or LPR living in their household that makes them potentially eligible for an immigrant visa or adjustment to LPR status. An additional 5.32 million and 456,000 persons (respectively) who live in these households would be indirectly affected by the proposed rule.

However, CMS's estimates significantly understate the number of persons who could be directly and indirectly affected by the rule for several reasons. First, the estimates do not include undocumented persons or nonimmigrants who are potentially eligible for a family-based visa

20 Id., V L 2.

21 As detailed in the Appendix, the first step in CMS's estimation process was to derive detailed estimates of the undocumented population residing in the United States in 2016. Those estimates are based on information collected in the US Census Bureau's annual American Community Survey (ACS). The procedures used to derive the estimates are outlined in the Appendix and are described in detail in Warren (2014). Next, CMS selected all of the households in the survey that had at least one undocumented resident. Finally, it examined the relationship of each undocumented resident to other members of the household to determine whether the undocumented resident was eligible for an immigrant visa based on a relationship with a family member. The same procedure was followed for each nonimmigrant residing in the United States. 
based on a qualifying relationship to a US citizen or LPR, but who are not living in the same household as their US citizen or LPR family member. Second, they do not cover persons who may be eligible for an employment-based or diversity visa. Third, they do not include the millions of persons residing overseas - and, thus, not counted in the ACS - who are waiting for a visa to become available or who otherwise seek admission as an immigrant or nonimmigrant. Fourth, they do not cover nonimmigrants seeking a change or extension of nonimmigrant status, but only nonimmigrants seeking adjustment to LPR status. Fifth, in deriving estimates of undocumented residents, CMS assumes that, with some exceptions, spouses and minor children of US citizens are also citizens. ${ }^{22}$ This means that some spouses and minor children who overstayed their nonimmigrant (temporary) visas and then married US citizens are not included in the 2.25 million figure presented here. Sixth and of greatest consequence, the estimates provide a snapshot of those subject to the proposed rule (based on 2016 ACS data) at a fixed time. They do not include the countless persons - including US citizens and LPRs - whose immigration status, life prospects, or public benefit use would be negatively affected by the rule in future years.

Profiles of the two groups, as well as an examination of their relevant characteristics under the proposed rule, follow.

\section{Profile of Undocumented Population with Qualifying Family Relationship to a US Citizen or LPR, and Factors Relevant to Totality of Circumstances Test}

The 2.25 million undocumented persons come from 133 countries, with the largest numbers from Mexico (1.2 million), India $(140,000)$, El Salvador $(119,000)$, the People's Republic of China (PRC) $(86,000)$, Guatemala $(81,000)$, Honduras $(65,000)$, and the Philippines $(49,000)$. They live in virtually every US state, with the largest numbers in California $(634,000)$, Texas $(386,000)$, New York (149,000), Florida (136,000), Illinois $(94,000)$, and New Jersey $(90,000)$. 257,000 live in the Los Angeles Metropolitan Statistical Area (MSA), 222,000 in the New York City MSA, 118,000 in the Houston MSA, 89,000 in the Chicago MSA, and about 70,000 in the Miami MSA.

The ACS does not collect information on most of the programs that would be considered in public charge determinations under the rule. In addition, the only individual (as opposed to household) public benefit use variables tracked by the ACS are welfare and Medicaid. Only 17,300 (0.8 percent) of the 2.25 million reported receiving welfare, and none reported receiving Medicaid. Among the other characteristics of this population:

- 818,000 (36 percent) are Hispanic, 414,000 (18 percent) are Asian (not Hispanic), 143,000 White (non-Hispanic), and 100,000 Black (not Hispanic).

- They live in 1.6 million households that have a median income of $\$ 56,000$.

- 379,000 are married to a US citizen and 826,000 to a legal non-citizen.

22 Nonimmigrants that overstay visas and then marry US citizens are eligible to adjust to LPR status without numerical restrictions. The best assumption for assigning legal status in the ACS data is that all noncitizens that are married to US citizens are legal residents. Although this is likely to be correct in most cases, an unknown number of nonimmigrant overstays who marry US citizens do not adjust status. These overstays - and their children in some cases - should be included in the study, but are not. 
- 2.1 million US-born children live in their households, including 1.7 million under the age of 21.

- 1.43 million have lived in the United States for at least 10 years, and 556,000 for 20 years or more.

- 1.32 million (59 percent) of those aged five and older speak English well or very well.

- 332,000 aged 3 or over are enrolled in school.

- 1.98 million fall between the working ages of 18 and 61 .

- $\quad 1.23$ million aged 16 and older are employed and 96,000 are unemployed but seeking work.

- 1.73 million live in families that earn at least 125 percent of the 2016 poverty threshold. ${ }^{23}$

- 218,000 work in the construction industry, 170,000 in restaurants and other food services, 48,000 in landscaping, 45,000 in services to buildings and dwellings, and 40,000 in crop production.

Many of the above factors would be considered in a totality of the circumstances determination. Of the 2.25 million undocumented residents examined in this study, the following possess characteristics -- which are not mutually exclusive - that mitigate against a finding of inadmissibility:

- 1.98 million are within the prime working ages of 18 to 61.

- 982,000 live in families that earn at least 250 percent of the poverty threshold (a highly weighted factor under the proposed rule).

- 1.2 million are employed, including 160,000 who are self-employed.

- 286,000 work in skilled occupations.

- 1.32 million speak English well or very well.

- 1.2 million individuals aged 18 or over have at least a high school diploma, including 361,000 with a bachelor's degree or higher.

- 1.1 million have private health insurance coverage.

By contrast, the following, non-exclusive groups possess characteristics that mitigate against admissibility:

- 529,000 live in families that earn less than 125 percent of the poverty threshold.

- 96,000 are unemployed.

- 825,000 aged 18 and over have less than a high school diploma or its equivalent.

- 306,000 do not speak English.

- 55,000 have ambulatory, cognitive, or independent living difficulties. 
The actual numbers of persons who would be found inadmissible under the proposed rule cannot be estimated with precision because: (1) many individuals and households possess a combination of positive and negative characteristics (as set forth in the rule); (2) USCIS officers enjoy a level of discretion in evaluating individual cases based on the totality of their circumstances, including factors not detailed in the proposed rule; and (3) CMS's aggregate data does not permit a more detailed analysis.

That said, a substantial number of undocumented immigrants who could be eligible for LPR status based on a qualifying family relationship to a US citizen or LPR have characteristics -like household income of less than 125 percent of the poverty threshold and less than a high school education - that weigh in favor of inadmissibility. By and large, nonimmigrants are less likely to be affected by the proposed rule than undocumented immigrants.

\section{Profile of Nonimmigrants with Qualifying Family Relationship to a US Citizen or LPR and Factors Relevant to Totality of Circumstances Test}

The 212,000 nonimmigrants who would be directly affected by the rule come from 124 countries, with the largest numbers from Mexico $(17,400)$, India $(15,600)$, the People's Republic of China $(14,800)$, the Philippines (13,300), Vietnam $(6,500)$, Canada $(6,400)$, Brazil $(6,000)$, the Dominican Republic $(5,400)$, Colombia $(4,700)$, Pakistan $(4,600)$, Korea $(4,500)$, and Jamaica $(4,400)$. They live in virtually every US state, with the largest numbers in California $(41,900)$, New York $(21,500)$, Texas $(20,800)$, Florida $(20,600)$, Illinois $(9,400)$, and New Jersey $(9,000)$. They are particularly concentrated in major cities, including 26,400 in the New York City metropolitan statistical area (MSA), 15,300 in the Los Angeles MSA, 10,900 in the Miami MSA, 9,100 in the Chicago MSA, and 8,000 in the Houston MSA. Among other characteristics:

- They live in 182,000 households that have a median income of $\$ 84,000$.

- 144,000 are married to a US citizen.

- 76,000 (36 percent) are Asian (not Hispanic); 59,000 (28 percent) White (not Hispanic); 32,000 (15 percent) Hispanic; and 24,000 (12 percent) Black (not Hispanic).

- 178,000 (86 percent) aged five or older speak English well or very well.

- 86,000 aged 3 or over are enrolled in school.

- 188,000 are between the ages of 18 to 61 .

- 112,000 aged 16 and older are employed and 15,000 are unemployed but seeking work.

- 185,000 (87 percent) live in families that earn at least 125 percent of the poverty threshold, including 147,000 (69 percent) in families that earn 250 percent or above the poverty threshold.

- 93,000 work in skilled occupations.

- 10,000 work in the hospital industry; 9,000 in computer systems design and related services; 8,700 in colleges, universities, and professional schools; and 7,000 in restaurants and other food services. 
Many of the above factors are potentially relevant to a public charge determination under the proposed rule. The following groups - which are not mutually exclusive - have characteristics that mitigate against inadmissibility:

- 188,000 are within the prime working ages of 18 to 61 .

- 112,000 aged 16 and older are employed, including 3,100 who are self-employed.

- 178,000 (86 percent) aged five and older speak English well or very well.

- 191,000 (97 percent) aged 18 or over have at least a high school diploma, including 123,000 (62 percent) with a bachelor's degree or higher.

- 93,000 work in skilled occupations.

- 154,000 have private health insurance coverage.

A relatively small number of nonimmigrants may be negatively impacted by the rule. The following, non-exclusive groups have characteristics that favor inadmissibility under the proposed rule:

- 27,000 live in families that earn less than 125 percent of the poverty threshold. ${ }^{24}$

- 15,000 are unemployed but seeking work.

- 6,200 (3 percent) aged 18 or over have less than a high school diploma or its equivalent.

- 6,600 (3 percent) do not speak English.

- 6,200 (3 percent) have ambulatory, cognitive, or independent living difficulties.

\section{Conclusion}

This study suggests that high numbers of working class persons would be found inadmissible under DHS's proposed public charge rule. Of the 2.25 million undocumented immigrants who are potentially eligible for LPR status based on a qualifying family relationship to a US citizen or LPR, 982,000 live in families that earn at least 250 percent of the poverty threshold. Yet, the 2.25 million also include many persons with low education levels, lack of proficiency in English, selfcare difficulty, and other factors that weigh in favor of inadmissibility under the proposed rule. Therefore, the rule represents a significant departure from the decades-long policy that employed, able-bodied immigrants should not generally be deemed inadmissible on public charge grounds.

More than that, the proposed rule poorly predicts who will become a public charge. Many immigrants with a limited knowledge of English, for example, work in sectors where strong English skills are not required and, in any event, become proficient in English over time. Many lesseducated immigrants own successful businesses. Family-based immigration promotes immigrant well-being and integration. The proposed rule would, thus, negatively impact many persons who are not financially dependent on the government and who are unlikely to become so. The rule overreaches. It would negatively affect low-income persons and their families, and represents a barrier to legal immigration and immigrant integration in large numbers of cases. 
The study also finds that nonimmigrants would be deemed inadmissible under the proposed rule at lower rates than the undocumented. A high proportion of nonimmigrants live in higher income households, and are highly educated, fluent in English, and employed in skilled occupations.

\section{APPENDIX}

\section{Overview of CMS Methodology}

Estimation of the undocumented population begins with the reported characteristics of non-US citizens (noncitizens) in the microdata of the ACS. The three relevant data items from the survey are country of birth, citizenship, and year of immigration. Noncitizens that entered the United States before 1982 are excluded because (a) pre-1982 entrants could have legalized under the Immigration Reform and Control Act of 1986 and (b) those who did not legalize have had 28 years (as of 2010) to leave the undocumented resident population. ${ }^{25}$

After selecting noncitizens that entered after 1981, the methodology involves three major steps: (1) applying a series of edits, referred to here as "logical edits," 26 to identify and remove as many legal residents as possible based on responses in the survey, (2) deriving separate population controls, for 145 countries or areas, for undocumented residents in 2010, and (3) using the population controls (also referred to as ratios) to make final selections of individual respondents in the ACS to be classified as undocumented residents. These procedures yield accurate and detailed estimates of the population each year, and the overall probability of being undocumented is about 90 percent.

As a next step, CMS identified noncitizen students and temporary workers who match the eligibility criteria for nonimmigrant visas, per the DOS guidelines for nonimmigrants. ${ }^{27} \mathrm{CMS}^{\prime} \mathrm{s}$ estimates do not count, for example, nonimmigrant visitors for business or pleasure.

Because the ACS does not identify LPRs as such, CMS defines LPRs as individuals who are neither citizens, undocumented, or nonimmigrants. Further, we assume that only biological parent-child relationships lead to eligibility for status adjustment. Finally, we assume that children cannot be undocumented unless at least one of their biological parents is undocumented.

To determine undocumented immigrants and nonimmigrants' eligibility to gain admission or to adjust status through a family member, we flagged individuals eligible to be petitioned by qualified family members (DOS-BCA 2018a,b). Specifically, we identify individuals eligible for LPR status based on a qualifying family relationship to a US citizen or LPR. We then count all individuals who fit these criteria, as well as the number of other individuals in their households. ${ }^{28}$

25 Undocumented residents can leave that population in four ways: they can adjust to legal status, be removed from the United States, leave the United States voluntarily, or, in a small number of cases, die.

26 The term logical edit refers to the process of determining probable legal status by examining survey data. Respondents were assigned to the legal category if they worked in occupations that generally require legal status, had the characteristics of legal temporary migrants, were immediate relatives of US citizens, received public benefits, such as Medicare and (in some cases) Medicaid, were from countries where two-thirds or more arrivals would be refugees, or were aged 60 or older at entry.

27 CMS also flagged as nonimmigrants the spouses and minor children of students and temporary workers.

28 CMS's estimates cover both visa overstayers and undocumented immigrants who illegally crossed a border. 


\section{References}

DOS-BCA (US Department of State, Bureau of Consular Affairs). 2018a. "Family-Based Immigrant Visas." https://travel.state.gov/content/travel/en/us-visas/immigrate/familyimmigration/family-based-immigrant-visas.html.

_. 2018b. "Directory of Visa Categories." https://travel.state.gov/content/travel/en/usvisas/visa-information-resources/all-visa-categories.html.

INS (Immigration and Naturalization Service). 1999. "Public Charge: INA Sections 212(a)(4) and 237(a)(5)." Memorandum from Michael A. Pearson, Executive Associate Commissioner, Office of Field Operations, to all Regional Directors, May 20. Washington, DC: USCIS. https://www.uscis.gov/ilink/docView/FR/HTML/FR/0-0-0-1/0-0-0-54070/0-0-054088/0-0-0-55744.html.

Kerwin, Donald, Daniela Alulema, and Mike Nicholson. 2018. Communities in Crisis: Interior Removals and Their Human Consequences. Nogales, AZ, New York, NY, and Washington, DC: Kino Border Initiative, Center for Migration Studies, and Jesuit Office of Justice and Ecology. https://doi.org/10.14240/rpt1118.

Singer, Audrey, and Ben Harrington. 2018. "Immigration: Frequently Asked Questions about 'Public Charge.'” Washington, DC: Congressional Research Service. https://fas.org/sgp/ crs/homesec/R45313.pdf.

Warren, Robert. 2014. "Democratizing Data about Unauthorized Residents in the United States: Estimates and Public-Use Data, 2010 to 2013." Journal on Migration and Human Security 2(4): 305-28. https://doi.org/10.1177/233150241400200403.

Warren, Robert, and Donald Kerwin. 2017. "Mass Deportations Would Impoverish US Families and Create Immense Social Costs." Journal on Migration and Human Security 5(1): 1-8. https://doi.org/10.1177/233150241700500101.

Wheeler, Charles. 2011. "Is Public Charge Relevant Anymore?" Washington, DC: CLINIC (Catholic Legal Immigration Network, Inc). https://cliniclegal.org/December2011/PublicCharge.

2018. "State Department redefines public charge standard." Washington, DC: CLINIC. https://cliniclegal.org/resources/state-department-redefines-public-charge-standard. 